\title{
GEOLOGIA DA SEQÜÊNCIA VULCANO-SEDIMENTAR DE ALPINÓPOLIS (MG)
}

\author{
SEBASTião G. CARVALHO*, PAULO C. SOARES**, MARIA C. ANTÔNIO** \\ ANTENOR ZANARDO* M MARCOS A.F. OLIVEIRA*
}

\begin{abstract}
GEOLOGY OF THE ALPINÓPOLIS VOLCANO-SEDIMENTARY SEQUENCE, MINAS GERAIS. The Alpinópolis Belt is located in the southern part of the State of Minas Gerais. It is one of several meta volcano-sedimentary sequences of the Morro do Ferro Greenstone Belt. As a result of surface geological mapping, petrological studies and subsurface exploration work conducted on the Alpinópolis region, a group of four rock suites have been recognized. The most important features of these four rock suites can be summarized as follows: The first suite comprises (a) chlorite-actinolite-tremolite schists with spinifex texture and minor olivine pseudomorphous; and (b) serpentinites with variable proportions of actinolite-tremolite-chlorite-talc-oli vine relicts and hornblende schists. The combined evidence of mineral assemblages, preserved primary textures and trace element chemistry indicate that these rocks were originally peridotites and pyroxenites of komatiitic affiliation. The second suite consists of a variable assemblage of plagioclase-homblende-actinolite-tremolite schists and amphibolites. The chemical and mineralogical features of this suite are consistent with a tholeiitic basalt origin. The third suite consists of metasedimentary rocks such as gamet-biotite schists, actinolite-tremolite-biotite schists, sillimanite-staurolite-biotite schists, gamet-antophylite schists, quartzites and minor iron formation units. The schists are interpreted to be isochemically metamorphosed tuffaceous, argillaceous and impure Fe-Mg-carbonate sediments. The aforementioned supracrustal rocks have been intruded by a number of granitoid rocks that consist of quartz, sódic-plagioclase and biotite. Near to and at the contact with the ultramafic flows, marundite rocks are observed. The policyclic tectonic-metamorphic and deformational processes which affected the area have given place to a complex, large scale structurally deformed framework and imprinted metamorphic patterns on the existing rock units and the associated $\mathrm{Ni}$-sulphide ore bodies.
\end{abstract}

Keywords: Metaultramafic rock,komatite, amphibotite, matamorphism.

\begin{abstract}
RESUMO A Seqüência Vulcano-Sedimentar de Alpinópolis é uma entre várias outras seqüências correlatas no Sudoeste do Estado de Minas Gerais, que integram o Greenstone Belt Morro do Ferro. Essas seqüências, como um todo, encontram-se embutidas tectonicamente por falhas ou estruturas sinformais em um embasamento graníticomigmatítico-gnáissico, regionalmente denominado de Complexo Campos Gerais. As litologias que compõem a seqüência foram reunidas em quatro suítes distintas, com base nos resultados de mapeamento geológico, estudos petrológicos e trabalhos de sondagens. Os fatores mais importantes das quatro suítes estão sumanzados abaixo. A primeira suíte corresponde a rochas metaultramáficas, constituídas por clorita-tretnolita xistos com pseudomorfos de olivina e textura spinifex, serpentinitos, talco xistos e homblenda xistos. A associação mineralógica, restos de texturas primárias e o quimismo dos elementos menores indicam que essas rochas foram originalmente peridotitos e piroxenitos de filiação komatiítica. A segunda suíte consiste de uma associação variável de plagioclásio, homblenda, actinolita, clorita e tremolita, gerando xistos e anfibolitos. Os dados mineralógicos e químicos dessa suíte são consistentes com uma origem a partir de basaltos toleíticos. A terceira suíte é formada por rochas metassedimentares tais como: granada-biotita xistos, actinolita-tremolita-biotita xistos, sillimanita-estaurolita-biotita xistos, granada-antofilita xistos, quartzitos, clinozoisita-actinolita fels e mais raramente formações ferríferas. Essas rochas são interpretadas como produtos metamórficos de sedimentos pelíticos, tufãceos e/ou margosos. Completando o quadro litológico, aparecem os granhóides intrudidos na seqüência supracrustal acima mencionada. Esses granitóides possuem composição trondhjemítica a monzogranítica e são compostos basicamente por quartzo, plagioclásio ácido (albita/oligoclásio), biotita e em alguns casos feldspato potássico. Localmente, no contato com as rochas ultramáficas, ocorrem concentrações de coríndon, gerando rocha denominada de marundito. Os eventos tectônico-metamórficos, de caráter policíclico, que atuaram na área resultaram numa geologia complexa, afetando a distribuição e a configuração espacial dos corpos rochosos e de minérios de Ni sulfetados associados.
\end{abstract}

Palavras-chave: Rocha metaultramáfica, komatiito, anfibolito, metamorfismo.

INTRODUÇÃo A existência de seqüências vulcanosedimentares tipo greenstone belt no sudoeste do Estado de Minas Gerais foi descrita pela primeira vez por Teixeira (1978), quando definiu o cinturão vulcano-sedimentar Morro do Ferro, nas imediações da cidade de Fortaleza de Minas. Posteriormente, trabalhos de vários outros autores, entre os quais se destacam Teixeira \& Dani (1979), Soares et al (1990), Carvalho \& Batista (1983), Carvalho et al. (1982), Choudhuri et al. (1982), Morales et al. (1983), Marchetto et ai. (1984), Teixeira et al. (1987) e Szabó (1989), permitiram uma melhor compreensão da distribuição local e regional segmentada desses cinturões, segundo várias faixas estreitas e descontínuas, balizadas por direção geral WNW-ESE, além de caracterizarem, em parte, os litotipos, metaniorfismo e quimismo deste cinturão.
Este trabalho reporta-se a estudos geológicos e petrográficos realizados em uma das faixas das seqüências vulcanosedimentares tipo greenstone belt localizada a sul da cidade de Alpinópolis e aqui designada como Seqüência VulcanoSedimentar Alpinópolis.

CONTEXTO GEOLÓGICO A Seqüência VulcanoSedimentar Alpinópolis é uma entre várias outras unidades correlatas que integram o Cinturão Vulcano-Sedimentar Morro do Ferro, nas proximidades das cidades de Fortaleza de Minas, Alpinópolis, Jacuí e Nova Rezende, todas localizadas no sudoeste do Estado de Minas Gerais.

De maneira geral, estas seqüências constituem entidades alóctones que se encontram embutidas tectonicamente, por falhas ou estruturas sinformais, em um embasamento

\footnotetext{
* Departamento de Petrologia e Metalogenia, Instituto de Geociências e Ciências Exatas, Universidade Estadual Paulista, Campus de Rio Claro, Av. 24-Q, 1515,

CEP 13506-900, Rio Claro, SP, Brasil

** Departamento de Geologia, Centro de Tecnologia, Universidade Federal do Paraná, Curitiba, PR, Brasil

*** Bolsista CNPq, Instituto de Geociências, Universidade de São Paulo, Caixa Postal 1348, CEP 05422-970, São Paulo, SP, Brasil
} 
granítico-migmatítico-gnáissico conhecido como Complexo Campos Gerais, correspondendo à margem tectonizada e cavalgada pelo Grupo Araxá/Canastra, do Cráton do São Francisco, cujo limite cratonizado está a cerca de $100 \mathrm{~km}$ a norte (Soares et al. 1990). A norte, a exposição destes terrenos tipo gnaisse-granito-greenstone belt é delimitada pelo Grupo Araxá/Canastra; a oeste, pelo Grupo Araxá/Canastra e sedimentos carboníferos da Bacia do Paraná; e, a sul, pelo Complexo Varginha- Guaxupé. Localmente, entre o Complexo Campos Gerais e o Grupo Araxá/Canastra afloram rochas atribuídas ao Grupo Bambuí (Teixeira et al. 1987) ou à seqüência metassedimentar de Carmo do Rio Claro (Heilbron et al. 1987, Simões et al 1988), como nos arredores de Carmo de Rio Claro (Fig. 1).
Nesse contexto, a Seqüência Vulcano-Sedimentar Alpinópolis é representada por quatro conjuntos litológicos principais, denominados de unidades metaultramáfica, metamáfica, metassedimentar e de intrusivas ácidas.

Com exceção da última unidade, as demais hospedam concentrações de sulfeto (principalmente piríta e pirrotita; subordinadamente calcopiríta, pentlandita e esfaleríta), que podem formar corpos mineralizados a $\mathrm{Ni}-\mathrm{Fe}$ de até quatro metros de espessura (Carvalho 1990).

UNIDADE METAULTRAMÁFICA A unidade metaultramáfica é composta por rochas diversas tais como clorita tremolita/actinolita xisto, serpentinitos, talco xistos e hornblenda xistos.

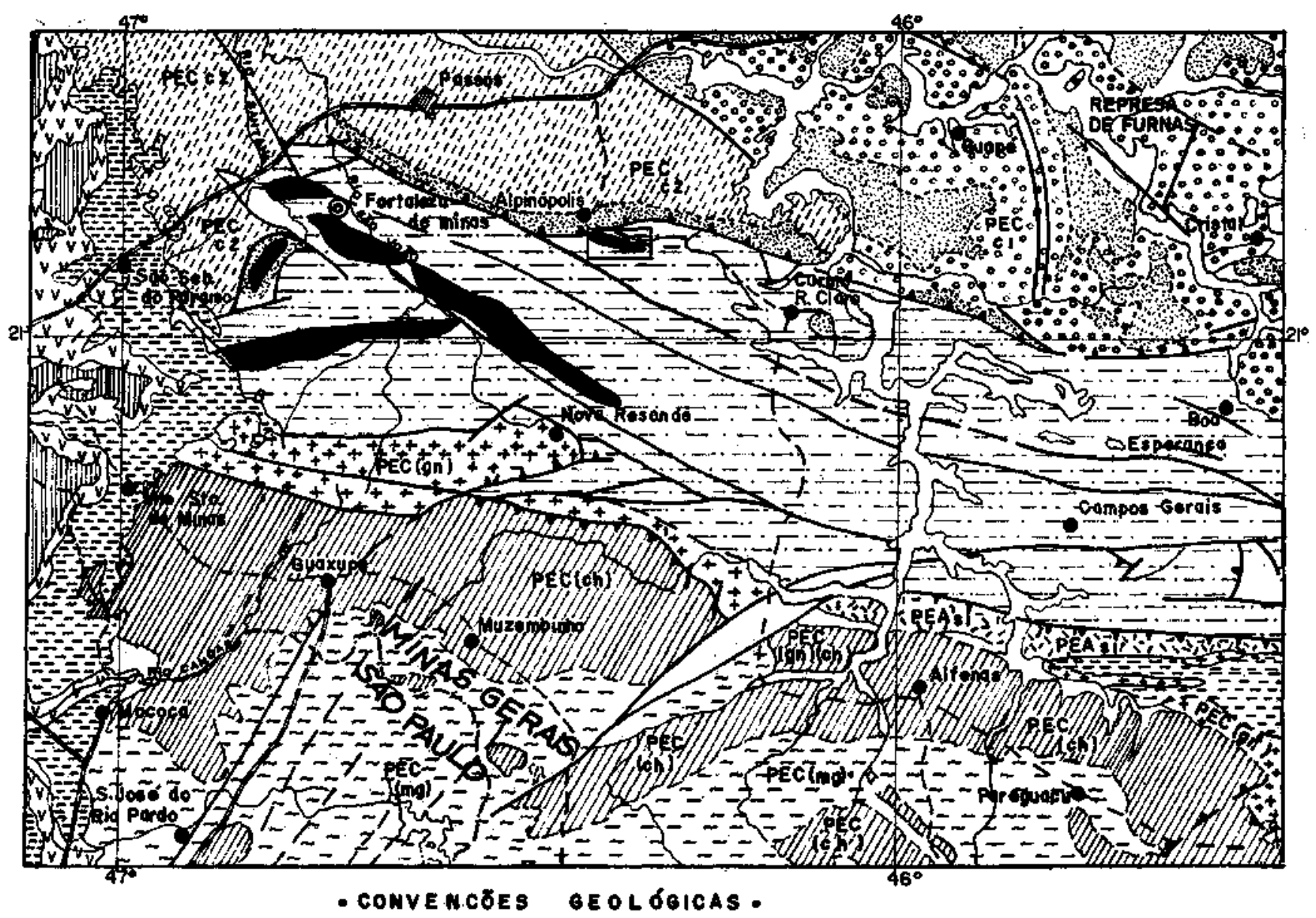

- convencós oeológlcas .
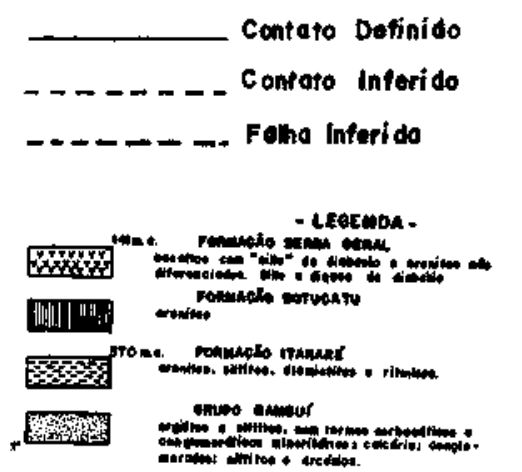
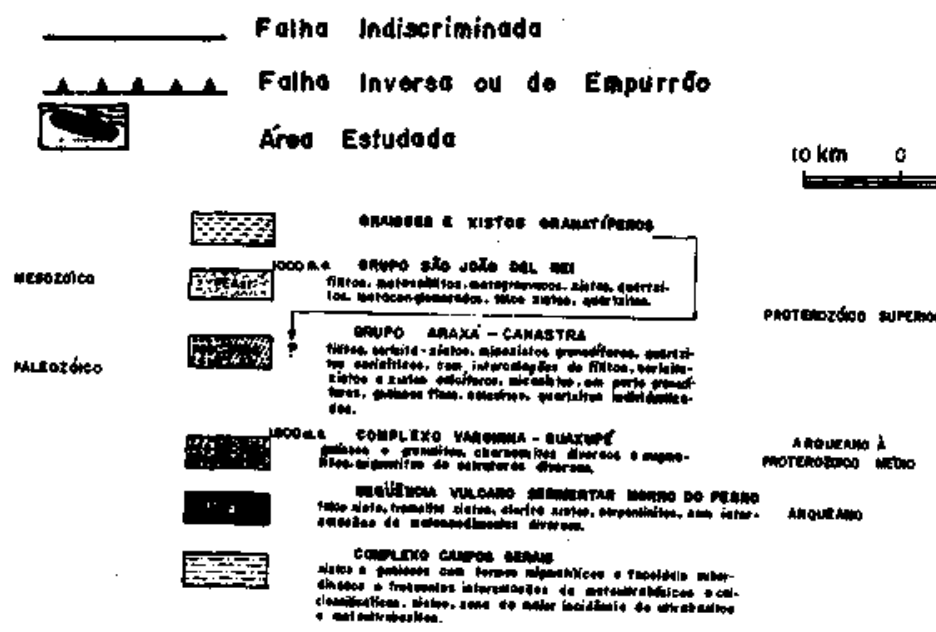

Figura 1 - Carta geológica dos arredores de Fortaleza de Minas e Alpinópolis (MG) Figure 1 - Geologic map of Fortaleza de Minas and Alpinópolis vicinity, Minas Gerais 
O litotipo clorita-tremolita/actinolita xisto é predominante nesta unidade e constitui os maiores corpos rochosos mapeados na área (Fig. 2).

Embora não seja possível discriminá-las em mapa, sob essa designação ocorrem variações litológicas que podem ser distinguidas tanto pela sua mineralogia, quanto pelos seus aspectos texturais. A figura 3 , que corresponde a perfis de furos de sondagens realizados na área, mostra, em parte, a individual! zação desses vários litotipos dentro do pacote vulcano-sedimentar. Nos clorita-tremolita/actinolita xistos, ocorrem ainda quantidades variadas localmente importantes de serpentina (antigorita e crisotila, Carvalho 1990), talco, carbonato e olivina, que podem modificar em alguns pontos a nomenclatura do referido litotipo. Com relação aos aspectos texturais, destaca-se a presença de pseudomorfos de olivina (agregado de serpentina, óxidos e, às vezes, talco ou clorita) e da textura spinifex.

Litotipos com essas características ocorrem principalmente nas porções nordeste e noroeste da área. Nos corpos localizados ao sul, essas feições são menos comuns, e as litologias se enriquecem em clinopiroxênio (endiopsídio). A textura spinifex pseudomorfisada é marcada por cristais aciculares de actinolita e/ou tremolita, clorita e, secundariamente, por hornblenda ou actinolita (Prancha 1 - Fotomicrografia 1). A olivina reliquiar forma cristais corroídos irregulares a ovóides e é constituída, principalmente, por crisolita e hialosiderita, e a clorita por penina e clinocloro (Prancha 1 - Fotomicrografia 2) (Carvalho 1990).

A composição química dessas rochas (Tabs, la e 1b, Figs. 4 e 5), suas texturas, as relíquias de sua mineralogia pretérita e os correspondentes produtos de transformação metamórfica (Tab. 2) sugerem origem a partir de vulcanismo komatiítico, compondo uma sucessão de derrames de lava ultramáfica (com topos definidos por fácies com textura spinifex), intercalados em pacotes (meta) sedimentares (Furos 8 e 9 , Fig. 3). Os dados químicos revelam que o litotipo "clorita-actinolita/tremolita xisto com pseudomorfos de olivina" é o termo menos diferenciado dentro do campo piroxenitoperidotito komatiítico (Figs. 4, Naldrett \& Turner 1977).

Os litotipos com textura spinifex pseudomórfica ocupam porções semelhantes no diagrama, com leve deslocamento em direção ao campo dos piroxenitos komatíticos, enquanto os litotipos com clinopiroxênio representam os termos mais diferenciados, posicionando-se no campo dos piroxenitos komatiíticos.

Foram mapeados 12 corpos de serpentinitos, com dimensões máximas de $500 \mathrm{~m}$ de comprimento por $100 \mathrm{~m}$ de largura, alongados segundo a direção NW a NNW e rotacionandos, localmente, para a direção WNW, que corresponde ao padrão regional. Em termos mineralógicos, esses corpos podem ser subdivididos em pelo menos dois litotipos. O primeiro e mais abundante eqüivale a clorita-tremolita serpentinito (Prancha 2 - Fotomicrografia 3) e o segundo a carbonato serpentinito (Prancha 2 - Fotomicrografia 4), sendo que em ambos ps tipos é possível observar restos de olivinas. Nos dois litotipos, o mineral de serpentina dominante é a lizardita, enquanto o anfibólio corresponde à tremolita e secundariamente à hornblenda (Carvalho 1990). Os minerais de clorita são representados essencialmente por clinocloro. A composição mineralógica dessas rochas, suas transformações metamórficas (Tab. 2) e seu posicionamento espacial (Figs. 2, 3 e 6) permitem supor que originariamente corresponderiam a derrames piroxeníticos e/ou peridotíticos komatííticos.

Quimicamente (tabelas 1a e 1b), são rochas enriquecidas em $\mathrm{MgO}$ e empobrecidas em $\mathrm{SiO}_{2}, \mathrm{Al}_{2} \mathrm{O}_{3}, \mathrm{CaO}$ e $\mathrm{TiO}_{2}$ (Figs. 4 e 5 ), plotando-se no diagrama de Jensen (1976 in viljoen et al. 1982) (Fig. 5A), posicionam-se no campo dos komatítos peridotíticos e piroxeníticos. Em diagrama de Viljoen et al. (1982) (Fig. 5B), posicionam-se na parte superior do campo dos komatiítos.

Corpos de talco xistos ocorrem dispersos na área, dos quais 20 puderam ser individualizados no mapa geológico. São mais abundantes e possantes na porção sul da área, onde atingem dimensões de até trezentos metros de comprimento por cerca de cinqüenta a cem metros de largura, com formato alongado segundo a direção regional NNW a NW-SE.

Mineralogicamente, além de talco, podem ocorrer proporções variadas de clorita, actinolita/tremolita e opacos (especialmente magnetita) (Tab. 2, Prancha 2 - Fotomicrografia 5).
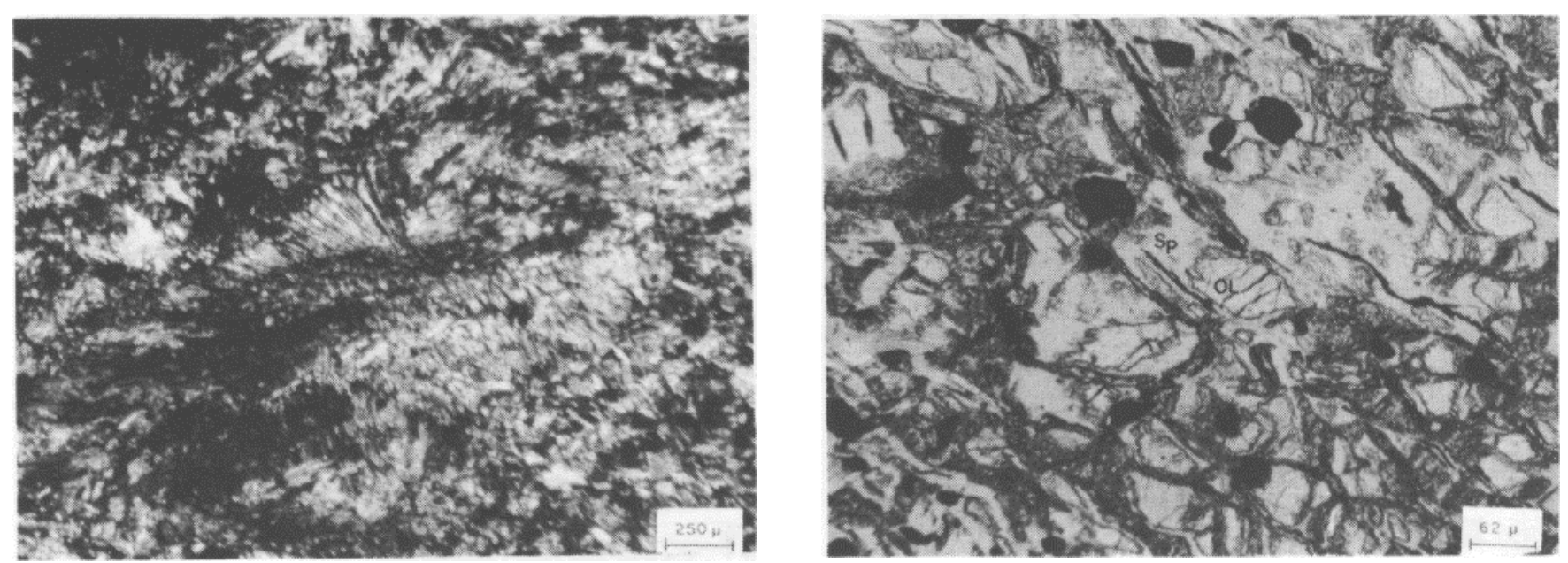

Prancha 1 - Fotomicrografia 1. Textura spinifex dada por cristais prismáticos de tremolita/actinolita com aspecto de pluma, no conjunto exibindo estrutura radial. Minerais com coloração clara a levemente cinza, correspondem a tremolita/actinolita enquanto os que se apresentam com coloração cinza escura são predominantemente clorita. Nicóis cruzados. Fotomicrografia 2. Núcleos mais preservados de olivina, sendo substituídos por serpentina das bordas para o centro. Ocupando as fraturas entre pseudomorfos de olivina ou ainda na própria olivina, ocorrem minerais opacos com predominância de magnetita. Secundariamente, há a presença de clorita e talco. $\boldsymbol{O L}=$ olivina, $\mathbf{S P}$ - serpentina. Nicóis paralelos

Chart 1 - Photomicrograph 1. Spinifex texture consisting of prismatic crystals of oriented tremolite - actinolite. White to light-gray colored minerals are tremolite and actinolite whereas dark-gray colored minerals are chlorite. Crossed nicols. Photomicrograph 2. Olivine crystals with a preserved nucleus and whose edges have been replaced by serpentine. Opaque minerals include magnetite either inside the olivine crystals or filling fractures between pseudomorphs after olivine. Minor secondary minerals include chlorite and talc $(\mathbf{O L}=$ olivine, $\mathbf{S P}=$ serpentine $)$. Plain light 


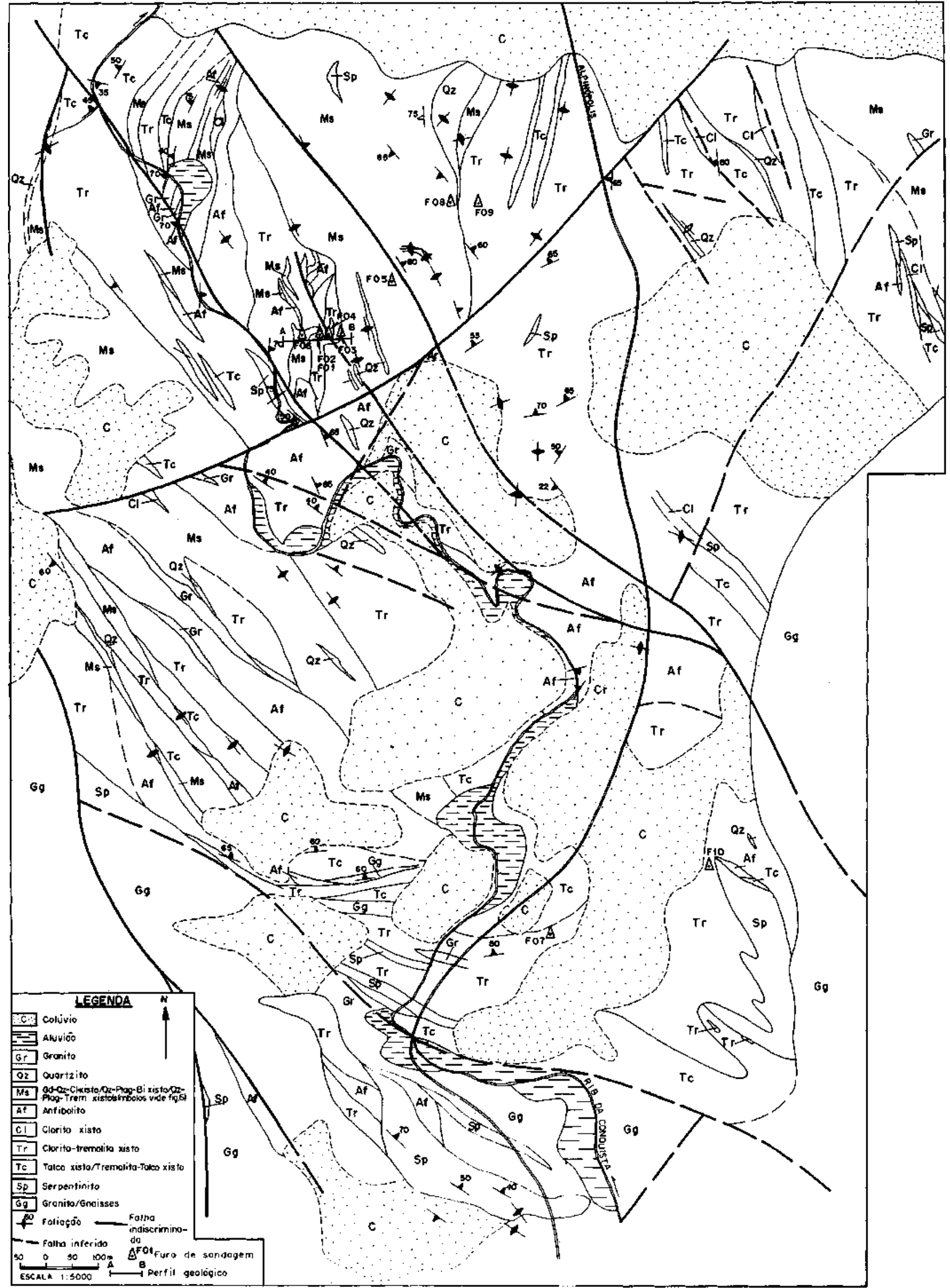

Figura 2 - Mapa geológico da área de Ribeirão da Conquista

Figure 2 - Geologic map of the Ribeirão da Conquista area 
A origem desses litotipos é interpretada como possivelmente ligada a processos de transformação metamórfica de rochas komatiíticas. As relações de contatos em superfície entre este litotipo com metaperídotitos/metapiroxenitos (Figs. 2) e em profundidade (Figs. 3 e 6 ) parecem corroborar esta interpretação.

Corpos de hornblenda xistos não puderam ser mapeados em superfície, mas foram detectados em furos de sondagens (Fig. 3, F01 e F02). Mineralogicamente, são constituídos por hornblenda, augita e titanita, além de outros minerais secundários (Tab. 2, Prancha 2 - Fotomicrografia 6) (Carvalho 1990). Quimicamente, apresentam-se como os termos mais diferenciados da unidade metaultramáfica, colocando-se no campo dos komatiítos basálticos (Figs. 4 e 5 ).
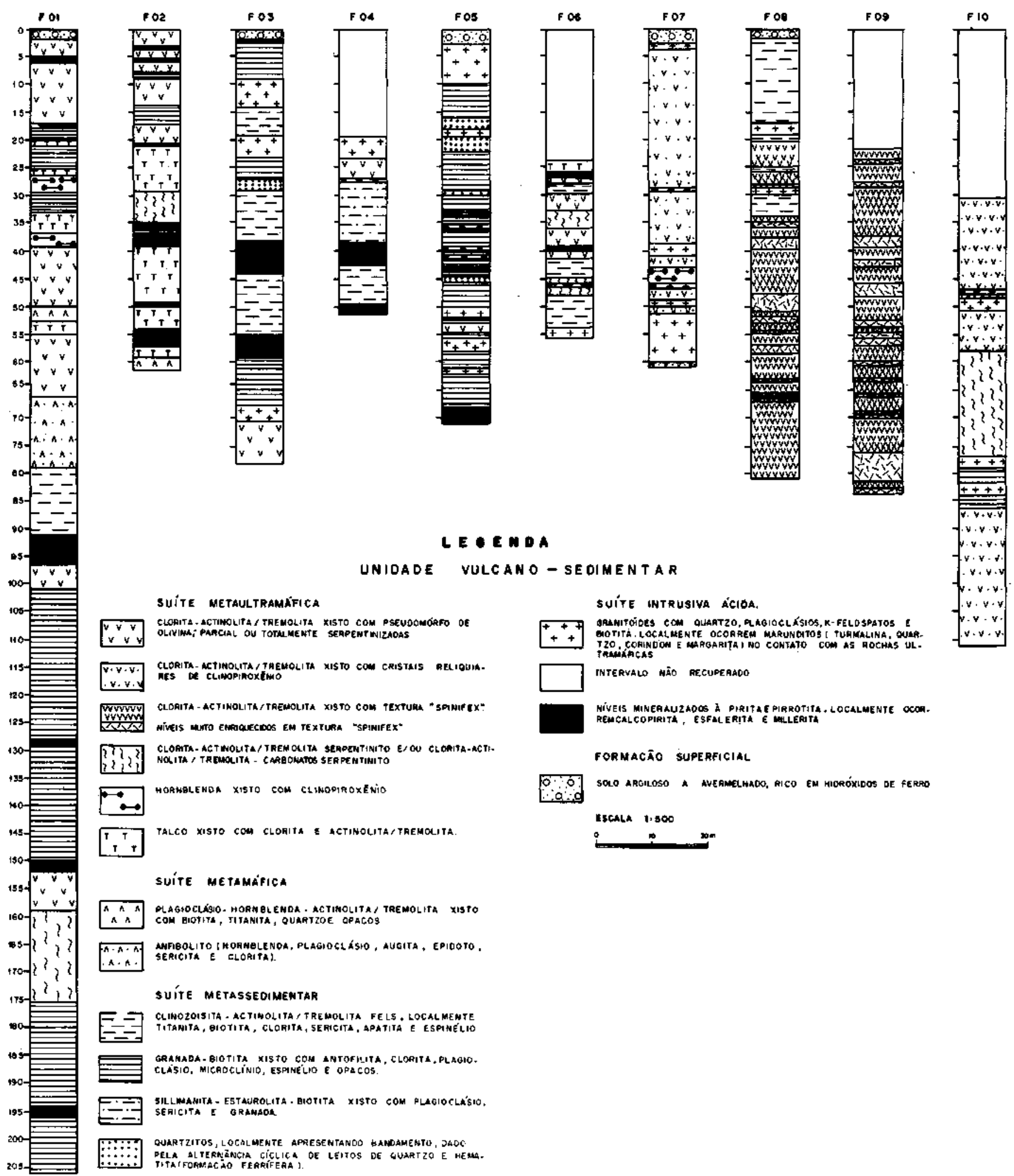

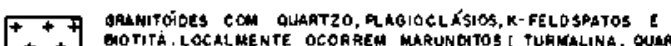

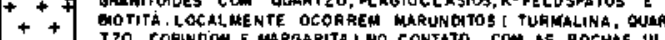

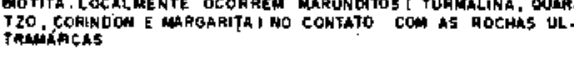

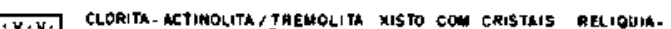

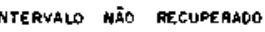

MIVEIS MINEALIJZAOOS I PRRITAE PIRROTITH, LOCALUEMTE COOMREE CALCOPIRITA, ESFAL ERITH E WLLLFITA

F ORHACAO SUPERFICIAL

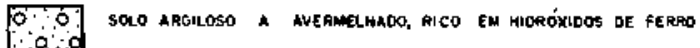

techle isoo

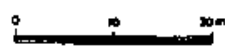

Figura 3 - Perfis litológicos das sondagens realizadas na Seqüencia Vulcano-Sedimentar de Alpinópolis (MG)

Figure 3 - Lithologic record from diamond drilling across the Volcanosedimentary Sequence of Alpinópolis, Minas Gerais 
Tabela la -Análise química dos elementos maiores e traços em algumas rochas da Seqüência Vulcano-Sedimentar de Alpinópolis $(M G)$, área de Ribeirão da Conquista (10 análises realizadas pelo laboratório da GEOSOL). Para dosagem dos elementos maiores, foi utilizado o método de espectofotometria de absorção atômica e para os elementos menores e traços o método de espectometria de plasma ICP. * ppm

Table la - Major and trace element content in rocks from the Volcanosedimentary Sequence of Alpinopolis at Ribeirão da Conquista, Minas Gerais. (Major element analysis by AAS and trace elements analysis by ICP were undertaken by Commercial laboratory of GEOSOL)

\begin{tabular}{|c|c|c|c|c|c|c|c|c|c|c|}
\hline Amostra & $\begin{array}{c}\text { F01- } \\
29,75 \mathrm{~m}\end{array}$ & $\begin{array}{c}\text { F06- } \\
24,0 \mathrm{~m}\end{array}$ & $\begin{array}{c}\text { F07- } \\
35,95 \mathrm{~m}\end{array}$ & $\begin{array}{c}\text { F08- } \\
77,90 \mathrm{~m}\end{array}$ & $\begin{array}{c}\text { F09- } \\
59,40 \mathrm{~m}\end{array}$ & $\begin{array}{c}\text { F10- } \\
47,0 \mathrm{~m}\end{array}$ & RC-5B & $\begin{array}{l}\text { RC- } \\
510\end{array}$ & $\begin{array}{c}\text { Fol- } \\
163,50 \mathrm{~m}\end{array}$ & $\begin{array}{c}\text { F06- } \\
57,90 \mathrm{~m}\end{array}$ \\
\hline $\mathrm{SiO}_{7} \%$ & 54,20 & 55,00 & 53,00 & 46,70 & 50,60 & 45,90 & 52,60 & 43,60 & 43,90 & 40,60 \\
\hline $\mathrm{TiO}_{2} \%$ & 1,20 & 0,32 & 0,44 & 0,42 & 0,38 & 0,98 & 0,66 & 0,43 & 0,09 & 0,27 \\
\hline $\mathrm{Al}_{2} \mathrm{O}_{3} \%$ & 14,40 & 2,20 & 2,70 & 5,20 & 4,30 & 6,10 & 4,00 & 5,20 & 0,63 & 3,80 \\
\hline $\mathrm{Fe}_{2} \mathrm{O}_{3} \%$ & 2,70 & 6,20 & 2,30 & 5,50 & 4,00 & 6,90 & 4,00 & 9,70 & 8,20 & 8,80 \\
\hline $\mathrm{FeO} \%$ & 6,36 & 2,45 & 5,06 & 5,78 & 5,78 & 4,62 & 6,50 & 4,91 & 1,73 & 2,89 \\
\hline MnO \% & 0,17 & 0,09 & 0,19 & 0,20 & 0,20 & 0,07 & 0,21 & 0,20 & 0,18 & 0,16 \\
\hline $\mathrm{MgO} \%$ & 7,00 & 27,20 & 16,50 & 23,40 & 19,70 & 22,40 & 15,00 & 26,80 & 35,20 & 33,50 \\
\hline $\mathrm{CaO} \%$ & 9,90 & 1,80 & 17,80 & 7,80 & 9,80 & 8,10 & 14,90 & 1,60 & 2,50 & 1,80 \\
\hline $\mathrm{Na}_{2} \mathrm{O} \%$ & 2,90 & 0,03 & 0,36 & 0,30 & 0,36 & 0,10 & 0,48 & 0,09 & 0,04 & 0,06 \\
\hline $\mathrm{K}_{2} \mathrm{O} \%$ & 0,79 & 0,01 & 0,13 & 0,02 & 0,11 & 0,07 & 0,24 & 0,04 & 0,01 & 0,01 \\
\hline $\mathrm{P}_{2} \mathrm{O}_{5} \%$ & 0,12 & $<0,05$ & 0,05 & $<0,05$ & $<0,05$ & $<0,05$ & $<0,05$ & $<0,05$ & $<0,05$ & $<0,05$ \\
\hline $\mathrm{H} 2 \mathrm{O}^{-} \%$ & 0,05 & 0,41 & 0,08 & 0,08 & 0,08 & 0,13 & 0,32 & 0,54 & 0,06 & 0,09 \\
\hline $\mathrm{H} 2 \mathrm{O}^{+} \%$ & 0,14 & 3,21 & 0,51 & 3,62 & 2,51 & 3,76 & 1,17 & 5,91 & 6,95 & 7,31 \\
\hline $\mathrm{CO}_{3} \%$ & 0,10 & 0,30 & 0,75 & 0,20 & 1,40 & 0,10 & 0,10 & 0,25 & 0,20 & 0,20 \\
\hline $5 \%$ & 0,04 & 0,54 & 0,16 & 0,05 & 0,16 & 0,02 & 0,02 & 0,01 & 0,11 & 0,03 \\
\hline Total \% & 100,07 & 99,81 & 100,13 & 99,32 & 99,43 & 99,30 & 100,25 & 99,33 & 99,85 & 99,57 \\
\hline${ }^{*} \mathrm{CO}_{0}$ & 81 & 200 & 76 & 114 & 97 & 130 & 114 & 124 & 81 & 135 \\
\hline${ }^{*} \mathrm{Cr}$ & 410 & 2000 & 700 & 3200 & 3200 & 3900 & 395 & 5000 & 2040 & 1560 \\
\hline${ }^{* \mathrm{Ni}}$ & 144 & 3300 & 640 & 1600 & 1600 & 1300 & 700 & 1140 & 1480 & 2600 \\
\hline$\% \mathrm{~V}$ & 310 & 142 & 300 & 240 & 290 & 280 & 370 & 164 & 80 & 230 \\
\hline${ }^{*} \mathrm{Cu}$ & 50 & 200 & 635 & 30 & 61 & 104 & 565 & 28 & 18 & 6 \\
\hline$* \mathrm{~Pb}$ & 5 & 3 & 8 & 8 & 6 & 12 & 19 & 10 & 8 & 12 \\
\hline$* \mathrm{Zn}$ & 84 & 74 & 258 & 44 & 66 & 110 & 94 & $\overline{176}$ & 56 & 72 \\
\hline${ }^{*} \mathrm{Li}$ & 27 & 9 & 11 & $<5$ & 7 & 16 & 13 & $<5$ & $<5$ & $<5$ \\
\hline${ }^{*} \mathrm{~B}$ & - & - & 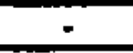 & - & - & $=$ & $=$ & $\div$ & $=$ & - \\
\hline *Ba & 79 & $<20$ & $<20$ & 22 & 25 & $<20$ & $<20$ & 20 & $<20$ & $<20$ \\
\hline *SI & - & - & $\overline{-}$ & - & $\overline{-}$ & $=$ & $\overline{-}$ & $=$ & $=$ & $=$ \\
\hline$* \mathrm{Zr}$ & 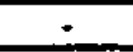 & $=$ & $=$ & $=$ & $=$ & 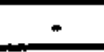 & 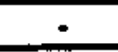 & $=$ & $=$ & $=$ \\
\hline$* \mathrm{Y}$ & 32 & 16 & 26 & 23 & 23 & 22 & 33 & 16 & 14 & 18 \\
\hline
\end{tabular}

UNIDADE METAMÁFICA Esta unidade é composta exclusivamente por anfibolitos e xistos básicos. Ocorrem principalmente na parte leste da área, onde foram discriminados catorze corpos, com dimensões máximas de $1.000 \mathrm{~m}$ de comprimento por $100 \mathrm{~m}$ de largura. Suas formas alongadas são condicionadas pela direção NW a NNW. Os estudos microscópicos revelaram a possibilidade de subdividir essa unidade em dois litotipos distintos, caracterizados como anfibolito e plagioclásio-homblenda-actinolita/tremolita xisto (Carvalho 1990).

O anfibolito é constituído essencialmente por hornblenda, comumente alterando-se para actinolita. $\mathrm{O}$ segundo litotipo apresenta como minerais essenciais, hornblenda, actinolita e plagioclásio, representado por andesina/oligoclásio.

Localmente, observam-se concentrações de biotita que chegam a representar $40 \%$ do total da rocha. A mineralogia desses litotipos e suas transformações metamórficas (Tab. 3 A) sugerem como protólitos rochas basálticas, de composição toleítica. As análises químicas (Tab. 1) revelam que esses litotipos, dentre os demais, são os que apresentam maiores teores de $\mathrm{SiO}_{2}, \mathrm{TiO}_{2}, \mathrm{~K}_{2} \mathrm{O}, \mathrm{Al}_{2} \mathrm{O}_{3}$ e menores teores de $\mathrm{MgO}$, $\mathrm{Ni}$ e Co (Figs. 4), apontando para origem a partir de rochas basálticas toleíticas (Figs. 4 e 5 ).

UNIDADE METASSEDIMENTAR A unidade metassedimentar ocorre intercalada e em íntima associação com as rochas metavulcânicas, apresentando-se com dimensões variadas, que vão desde alguns centímetros de espessura (em furos de sondagens) até mais de $900 \mathrm{~m}$ de comprimento por $400 \mathrm{~m}$ de largura, em superfície, como é o caso para a porção norte-nordeste (Fig. 2) da área mapeada. Apresenta variada associação mineralógica, constituindo litotipos diversos, nãodiscriminados no mapa geológico, no qual foram reunidos como metassedimentos e quartzitos. Os metassedimentos correspondem a granada-biotita xistos; actinolita/tremolitabiotita xistos; estaurolita-sillimanita-biotita xistos (Prancha 3 - Fotomicrografia 7); granada-antofílita xistos (Prancha 3 - Fotomicrografia 8); e clinozoisita-actinolita fels (Prancha 3 - Fotomicrografia 9). Cabe ressaltar que os actinolita/ 
Tabela 1b-A nálise química dos elementos maiores e traços em algumas rochas da Seqüência Vulcano-Sedimentar de Alpinópolis (MG), área de Ribeirão da Conquista (13 análises realizadas pelo laboratório da British Petroleum). Para dosagem dos elementos maiores, foi utilizado o método de espectofotometria de absorção atômica e para os elementos menores e traços o método de espectometria de plasma ICP. $\mathbf{F e} \boldsymbol{O}=$ ferro total; * ppm

Table 1 b - Major and trace element content in rocks from the Vblcanosedimentary Sequence of Alpinópolis at Ribeirão da Conquista, Minas Gerais. (Major element analysis by AAS and trace elements analysis by ICP were undertaken by Commercial laboratory of British Petroleum in Rio de Janeiro

\begin{tabular}{|c|c|c|c|c|c|c|c|c|c|c|c|c|c|}
\hline Amostra & $\begin{array}{c}\text { F01- } \\
\text { 56,00m }\end{array}$ & $\begin{array}{c}\text { F01- } \\
76,00 \mathrm{~m}\end{array}$ & $\begin{array}{c}\text { Fol- } \\
154,40 \mathrm{~m}\end{array}$ & $\begin{array}{c}F 06- \\
42,00 m\end{array}$ & $\begin{array}{c}708- \\
48,20 \mathrm{~m}\end{array}$ & $\begin{array}{c}\text { Fol- } \\
64,30 \mathrm{~m}\end{array}$ & $\begin{array}{c}\text { F09- } \\
32,40 \mathrm{~m}\end{array}$ & $\begin{array}{c}\mathrm{F} 09- \\
76,50 \mathrm{~m}\end{array}$ & $\begin{array}{c}\text { Fo9- } \\
81,70 \mathrm{~m}\end{array}$ & $\begin{array}{c}F 01- \\
165,50 \mathrm{~m}\end{array}$ & $\begin{array}{c}\text { Fol- } \\
190,00 \mathrm{~m}\end{array}$ & $\begin{array}{c}\text { Fo6- } \\
33,75 \mathrm{~m}\end{array}$ & $\begin{array}{c}\text { Fo1- } \\
205,00 \mathrm{~m}\end{array}$ \\
\hline $\mathrm{SiO}_{2} \%$ & 54,81 & 55,62 & 51,77 & 49,03 & 44,37 & 44,86 & 49,99 & 48,11 & 30,36 & 40,94 & 38,23 & 40,94 & $\$ 9,85$ \\
\hline $\mathrm{TiO}_{2} \%$ & 0,70 & 1,00 & 0,60 & 0,60 & 0,50 & 0,50 & 0,30 & 0,60 & 0,40 & 0,08 & 0,08 & 0,12 & 0,90 \\
\hline $\mathrm{Al}_{2} \mathrm{O} \%$ & 4,90 & 12,80 & 4,00 & 480 & 5,70 & 6,40 & 4,40 & 3,90 & 4,60 & 0.85 & 0,80 & 0,83 & 17,20 \\
\hline Fe0 \% & 14,40 & 19,00 & 13,50 & 13,00 & 12,90 & 1390 & 9,90 & 12,90 & 9,40 & 11,50 & 13,00 & 13,30 & 8,40 \\
\hline $\operatorname{MnO} \%$ & 0,22 & 0,22 & 0,21 & 0,17 & 0,13 & 0,17 & 0,18 & 0,17 & 0,17 & 0,08 & 0,08 & 0,08 & 0,17 \\
\hline $\mathrm{MPO}$ & 11,70 & 1,70 & 14,70 & 16,20 & 22,50 & 23,50 & 20,10 & 19,40 & 2130 & 34,30 & 32,00 & 32,20 & 3,4 \\
\hline $\mathrm{N}_{2} \mathrm{O} \%$ & 2,70 & 6,60 & 20 & 2,00 & 1,60 & 2,00 & 2,30 & 2,10 & 1,50 & 1,30 & 1,60 & 1,70 & 6,60 \\
\hline $\mathrm{k}, \mathrm{O} \%$ & 0,14 & 0,61 & 0,06 & 0,20 & 0,06 & 0,06 & 0,06 & 0,06 & 0,06 & 0,06 & 0,06 & 0,06 & 1,20 \\
\hline $\mathrm{P}_{2} \mathrm{O}_{5} \%$ & 0,05 & 0,16 & 0,07 & 0,07 & 0,01 & 0,07 & 0,05 & 0,05 & 0,05 & 0,01 & 0,01 & 0,01 & 0,02 \\
\hline $\mathrm{PPC} \%$ & 0,54 & 0,61 & 0,44 & 2,80 & 5,05 & 5,20 & 2,09 & 2,82 & 3,33 & 10,33 & 10,17 & 10,45 & 2,21 \\
\hline $\mathrm{s} \%$ & 0,05 & 0,42 & 0,05 & 0,28 & 0,05 & 0,05 & 0,05 & 0,05 & 0.05 & 0,21 & 0,15 & 0,05 & 0,27 \\
\hline Total \% & 101,71 & 103,44 & 99,20 & 99,35 & 98,97 & 102,61 & 98,72 & 99,16 & 97,42 & 100,16 & 96.78 & 100,24 & 102,32 \\
\hline${ }^{*} \mathrm{Co}$ & 72 & 50 & 80 & 89 & 93 & 102 & 84 & 90 & 80 & 144 & 124 & 114 & 65 \\
\hline $4 \mathrm{Ni}$ & 83 & 480 & 25 & 510 & 360 & 400 & 200 & 126 & 360 & 3000 & 2530 & 2080 & 390 \\
\hline$+V$ & 201 & 39 & 177 & 131 & 184 & 195 & 114 & 172 & 132 & 24 & 35 & 32 & 160 \\
\hline${ }^{\circ} \mathrm{Cu}$ & 19 & 51 & 5 & 49 & 5 & 5 & 25 & 29 & 11 & 12 & 46 & 24 & 54 \\
\hline $\mathrm{Pb}_{\mathrm{b}}$ & 15 & 41 & 86 & 15 & 35 & 15 & 35 & 15 & 15 & 15 & 15 & IS & 61 \\
\hline $\mathrm{Zn}$ & 144 & 211 & 173 & 111 & 70 & 85 & 65 & 87 & 85 & 211 & 96 & 282 & 12] \\
\hline${ }^{*} \mathrm{Ll}$ & 11 & 57 & 10 & 31 & 22 & 8 & 2.5 & 14 & 2,5 & 14 & 24 & 22 & 100 \\
\hline H & 66 & 65 & 60 & 67 & 34 & 74 & 52 & 39 & 29 & 178 & 140 & 117 & 128 \\
\hline$+\mathrm{Ba}$ & 72 & 236 & 15 & 5 & 5 & 5 & 12 & 20 & 5 & 5 & 5 & 5 & 322 \\
\hline $\mathrm{Sr}$ & 64 & 180 & 54 & 68 & 79 & 87 & 116 & 102 & 84 & 29 & 25 & 31 & 299 \\
\hline$Z_{I}$ & 36 & 84 & 40 & 37. & 36 & 34 & 18 & 33 & 28 & 5 & 5 & 5 & 152 \\
\hline$\$ Y$ & 10 & 19 & 9 & 9 & 7 & 7 & 7 & 11 & 10 & 2,5 & 2,5 & 2,5 & 25 \\
\hline
\end{tabular}

tremolita-biotita xistos e clinozoisita-actinolita fels podem tratar-se de derrames básicos fortemente modificados por processos metassomáticps e tectono-metamórficos. Os quartzitos, na sua maioria, respondem por rochas monominerálicas a quartzo. Localmente, pode ocorrer alternância cíclica de leitos quartzosos e hematíticos, caracterizando possíveis formações ferríferas, sendo que os ortoquartzitos podem ser veios de quartzo cisalhados a temperaturas superiores a $300^{\circ} \mathrm{C}$ a altas taxas deformacionais e na presença de $\mathrm{H}_{2} \mathrm{O}$.

Em termos niineralógicos, os metassedimentos apresentam como minerais essenciais proporcões variadas de biotita, plagioclásio, almandina, clorita, sillimanita, estaurolita, antpfilita, quartzo, actinolita e clinozoisita e, acessoriamente, serícita, epídoto, apatita, espinélio e titanita (Tab. 3B). Com base nos minerais presentes e no contexto geológico, esses litotipos foram tentativamente interpretados como derivados de rochas sedimentares pelíticas-aluminosas, com contribuição tufácea e/ou carbonática.

INTRUSIVAS ÁCIDAS Os litotipos incluídos nessa unidade correspondem essencialmente a granitóides que ocorrem como corpos lenticulares posicionados ao longo de zonas de falhas e que, na porção nordeste da área, atingem dimensões máximas de $400 \mathrm{~m}$ de comprimento por $25 \mathrm{~m}$ de largura. Na parte sudoeste da área, foram individualizados, no campo, nove corpos granitóides, mas os trabalhos geológicos de detalhe (trincheiras, poços e sondagens) mostram que infiltrações de granitóides de menor porte são muito freqüentes por toda a área.

São rochas constituídas essencialmente por quartzo, plagioclásio e biotita, podendo ser hololeucocráticas, localmente. Nos contatos com litotipos ultrabásicos, desenvolve-se, muitas vezes, uma mineralogia à base de turmalinas, quartzo, feldspato, mica (margarítas) e coríndon, constituindo rochas denominadas de marunditos.

CONCENTRAÇÕES SULFETADAS Os corpos sulfetados que se hospedam nas rochas da Seqüência VulcanoSedimentar Alpinópolis são do tipo estratiforme com espessura média de um metro, podendo, localmente, chegar a quatro metros, em concentrações do tipo maciço, semi-maciço e disseminado.

A associação de minerais de minério que compõem esses níveis sulfetados é relativamente simples, constituindo-se em essência de pirrotita, pirita, esfalerita, pentlandita e calcopiríta, sendo os dois primeiros dominantes e, não raro, representando a totalidade de sulfelos. Além de sulfetos, ocorre ainda uma associação de óxidos formada principalmente por ilmenita, rutilo, magnetita e hematita (Carvalho 1990).

METAMORFISMO A reconstituição detalhada da evolução geológica da Seqüência Vulcano-Sedimentar Alpinópolis está longe de ser alcançada. A atuação dos eventos tectono-metamórficos, com caráter policíclico regional, resultou em uma geologia local excepcionalmente complexa, afetando a distribuição e configuração espacial dos litotipos (Figs. 2 e 5). Para Soares et al (1990), a área estudada foi palco de pelo menos quatro fases de deformação, deixando impressas nas rochas três foliações distintas, além de provocar o surgimento generalizado de falhamentos e zonas de cisalhamentos com orientações diversas.

Por esta razão, é difícil associar os eventos deformativos regionais a seus respectivos eventos metamórficos e conseqüentes mobilizações de elementos. $\mathrm{O}$ que se observa com relativa segurança é que as associações mineralógicas e suas 
Tabela 2 - Mineralogia e transformações metamôrficas na unidade metaultramáfica Table 2 - Mineralogy and nietamorphic changes of the metamorphosed ultramaflc unit

\begin{tabular}{|c|c|c|c|}
\hline \multicolumn{4}{|c|}{ UNIDADE METAULTRAMÁFICA METAULTRABÁSICA } \\
\hline LITOTIPO & $\begin{array}{l}\text { VARIAÇAO } \\
\text { MINERALOGICA }\end{array}$ & $\begin{array}{l}\text { TRANSFORMACOOES } \\
\text { METAMORFICAS } \\
\text { MAIS FREQUENTES } \\
\text { NOS LITOTIPOS }\end{array}$ & $\begin{array}{l}\text { POSSIVEL ROCHA } \\
\text { ORIGINAL }\end{array}$ \\
\hline $\begin{array}{l}\text { Clorita-Tremolita/ } \\
\text { Actinolita Xisto } \\
\text { com pseudomorios } \\
\text { de Olivinas }\end{array}$ & $\begin{array}{l}\text { Act Tremolita }=40-80 \% \\
\text { Serpentina }=10-50 \% \\
\text { Clorita }=0-25 \% \\
\text { Opacos }=5-10 \% \\
\text { Talco }=0-4 \% \\
\text { Carbonato }=0.3 \% \\
\text { Olivina }=0-3 \% \\
\end{array}$ & $\begin{array}{c}\text { तSerpentina } \\
\text { तTalco } \\
\text { Olivinas } \rightarrow \text { Act/Tremolita } \\
\text { yClorita } \\
\text { yOpacos } \\
\text { Actinolita } \rightarrow \text { Carbonato }\end{array}$ & Peridotitos \\
\hline $\begin{array}{l}\text { Clorita -Tremolita } \\
\text { Actinolita Xisto } \\
\text { com textura Spinifex }\end{array}$ & $\begin{array}{l}\text { Act } \sqrt{T} \text { remolita }=65-80 \% \\
\text { Clorita }=15-30 \% \\
\text { Opacos }=3-10 \% \\
\text { Olivinas }=0-2 \%\end{array}$ & $\begin{array}{l}\text { 7Act/Tremolita } \\
\text { Olivinas } \\
\text { MClorita }\end{array}$ & Peridotitos \\
\hline $\begin{array}{l}\text { Clorita -Tremolital } \\
\text { Actinolita Xisto } \\
\text { com Clinopiroxênio }\end{array}$ & $\begin{array}{l}\text { Act/Tremolita }=50-90 \% \\
\text { Clinopiroxênio }=10-45 \% \\
\text { Clorita }=0-15 \% \\
\text { Titanita }=0-5 \% \\
\text { Opacos }=0-5 \% \\
\text { Carbonato }=0-3 \% \\
\text { Epidoto = tracos }\end{array}$ & $\begin{array}{ll}\text { Clinopiroxênio } & \begin{array}{l}\text { mAct/Tremolita } \\
\boldsymbol{L}\end{array} \\
\text { yClorita }\end{array}$ & Piroxênitos \\
\hline Serpentinito & $\begin{array}{l}\text { Serpentina }=30-90 \% \\
\text { Act/Trenolita }=0-40 \% \\
\text { Clorita }=0-18 \% \\
\text { Opacos }=5-15 \% \\
\text { Carbonato }=0-12 \% \\
\text { Olivina }=0-5 \% \\
\text { Talco }=0-1 \% \\
\text { Clinopiroxênio }=0-1 \%\end{array}$ & $\begin{array}{c}\text { ATalco } \\
\text { OAct/Tremolita } \\
\text { Olivinas } \\
\text { YClorita } \\
\Downarrow \text { YSerpentina }\end{array}$ & Peridotitos \\
\hline Homblenda Xisto & $\begin{array}{l}\text { Hornblenda }=50-90 \% \\
\text { Clinopiroxênio }=0-40 \% \\
\text { Ferro Actinolita }=0-15 \% \\
\text { Titanita }=0-6 \% \\
\text { Carbonato }=0-5 \% \\
\text { Opacos }=0-5 \% \\
\text { Epidoto }=0-3 \% \\
\text { Apatita }=0-1 \% \\
\text { Quartzo }=0-1 \% \\
\text { Rutilo }=0-1 \%\end{array}$ & $\begin{array}{l}\text { Clinopiroxênio } \begin{array}{l}\text { Ferro Actinolita } \\
\qquad \text { Hornblenda } \\
\text { Act/Tremolita }\end{array} \\
\text { Rutilo } \rightarrow \text { Titanita }\end{array}$ & Piroxénitos? \\
\hline Talco Xisto & $\begin{array}{l}\text { Talco }=80 \% \\
\text { Clorita }=10 \% \\
\text { Opacos }=4 \% \\
\text { Act/Tremolita }=4 \% \\
\text { Serpentina }=2 \%\end{array}$ & $\begin{array}{l}\text { Act/Tremolita } \\
\text { Clorita } \rightarrow \text { Talco } \\
\text { Serpentina }\end{array}$ & Peridotitos \\
\hline
\end{tabular}

referidas transformações presentes na área em estudo marcam a presença de dois eventos metamórficos principais.

$\mathrm{O}$ primeiro atingiu uma temperatura mínima de $600^{\circ} \mathrm{C}$, compatível com os limites inferiores da fácies anfibolito (metamorfismo de médio grau). Como minerais diagnósticos deste evento, temos a presença de hornblenda, granada, sillimanita, estaurolita e antofilita, não estando descartada a possibilidade de que a oi i vi na e os piroxênios sejam metamórficos. Esses minerais se arranjam segundo as seguintes associações:

1. olivina + piroxênio (metapiroxenitos e metaperidotitos); 2. hornblenda + titanita + opacos (anfibolitos); 3. antofilita + biotita + quartzo (xistos e quartzitos); 4. estaurolita + sillimanita + biotita + quartzo (Fotomicrografia 7) (xistos e gnaisses); 5. sillimanita + granada + quartzo (xistos, quartzitos e gnaisses).
De acordo com Winkler (1976), a paragênese biotitaestaurolita é diagnostica do inicio do metamorfismo de grau médio (fácies anfibolito), enquanto a presença de sillimanita e antofilita são indicativas de temperaturas superiores a $600^{\circ} \mathrm{C}$ e a presença de almandina indica pressões superiores a 4 kbar (fácies anfibolito médio). Este evento metamórfíco associa-se à deformação intensa e dúctil, caracterizada como o evento deformacional mais antigo, observado na cobertura vulcano-sedimentar.

O segundo evento metamórfico, bem caracterizado na área, é atestado pela presença de clorita, tremolita, actinolita, serpentina, talco e carbonato em rochas ultramáficas; actinolita, sericita, clorita, clinozoísita, pistacita, albita, carbonato, titanita e leucoxênio em rochas máficas; sericita, clinozoísita, pistacita, actinolita/tremolita, albita, clorita e carbonato, além de granada relacionada com clorita e quartzo em zona de 

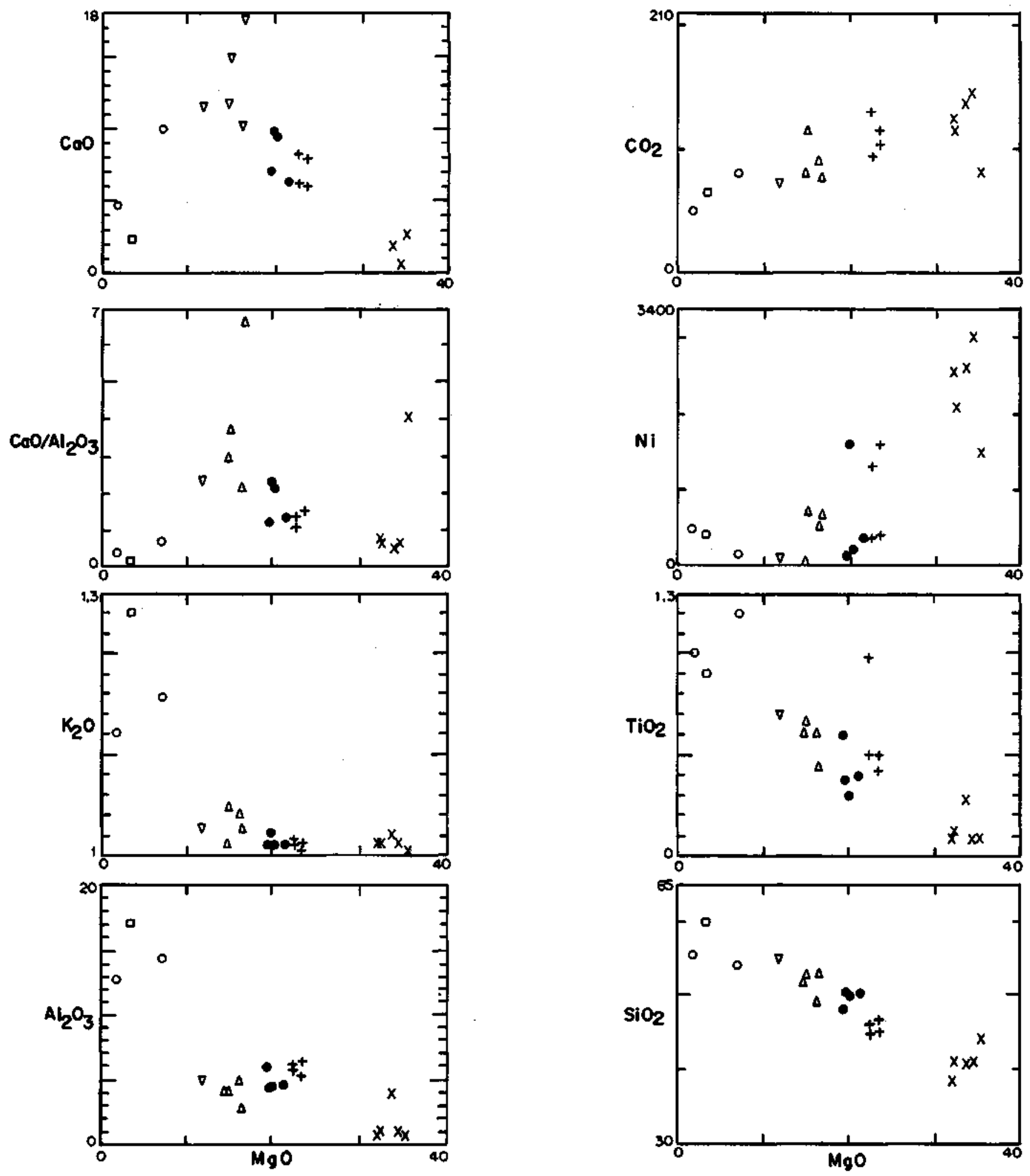

\section{LEGENDA}

$x$ - SERPENTINITOS

+ - CLCRITA ACTINOLITA-TREMOLITA XISTO COM PSEUDOMORFO DE OLIVIMA

$\nabla$ - hOANGLENOA XISTO

- clorita actinolita-themolta xisto com textura esoueletais

- ANFIBOLITO

a-CLORITA ACTINOLITA-TREMOLITA XISTO COM RESTO DE CLINO-

D- METASSEDIMENTO PIROXẼNIO

Figura 4 - Diagramas de variação $\mathrm{MgO}$ versus óxidos; $\mathrm{MgO}$ versus níquel e $\mathrm{MgO}$ versus $\mathrm{CaO} / \mathrm{Al}_{2} \mathrm{O}_{3}$ Figure 4 - Variation diagrams in which oxides, nickel and the ratio $\mathrm{CaO} / \mathrm{Al}_{2} \mathrm{O}_{3}$ are plotted against $\mathrm{MgO}$. 


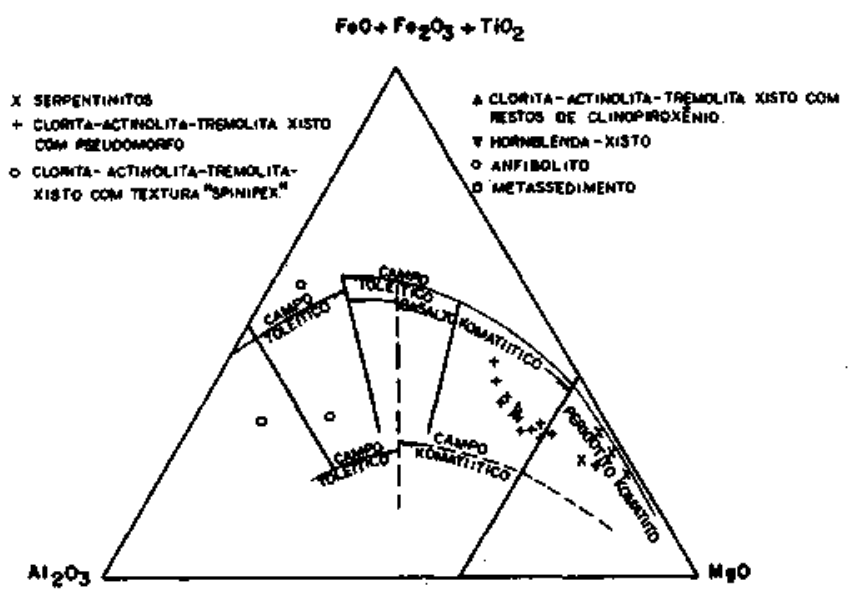

Figura $5 \mathrm{~A}$ - Diagrama $\left(\mathrm{FeO}+\mathrm{Fe}_{2} \mathrm{O}_{3}+\mathrm{TiO}_{2}\right)-\mathrm{Al}_{2} \mathrm{O}_{3}-\mathrm{MgO}$ das rochas metaultramáficas e metamáficas da área de Ribeirão da Conquista, Alpinópolis (MG) Figure $5 \mathrm{~A}$ - The $\left(\mathrm{FeO}+\mathrm{Fe}_{2} \mathrm{O}_{3}+\mathrm{TiO}_{2}\right)-\mathrm{Al}_{2} \mathrm{O}_{3}$ - $\mathrm{MgO}$ diagram for analyses of metamorphosed ultramafic and mafic rocks from the Ribeirão da Conquista area near Alpinópolis Minas Gerais

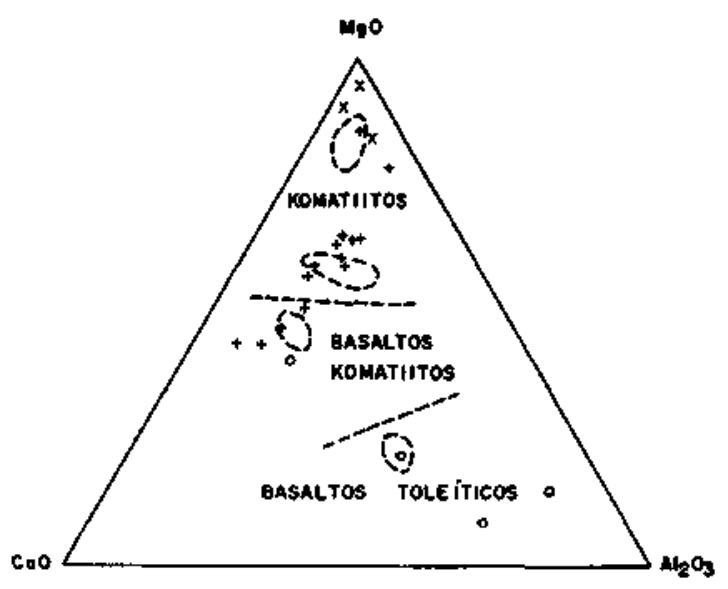

Figura 5B - Diagrama $\mathrm{CaO}-\mathrm{Al}_{2} \mathrm{O}_{3}-\mathrm{MgO}$ para rochas metaultramáficas e metamáficas da área de Ribeirão da Conquista, Alpinópolis (MG)

Figure $5 \mathrm{~B}-\mathrm{The} \mathrm{CaO}-\mathrm{Al}_{2} \mathrm{O}_{3}-\mathrm{MgO}$ diagram for analyses of metamorphosed ultramafic and mafic rocks from the Ribeirão da Conquista area near Alpinópolis, Minas Gerais

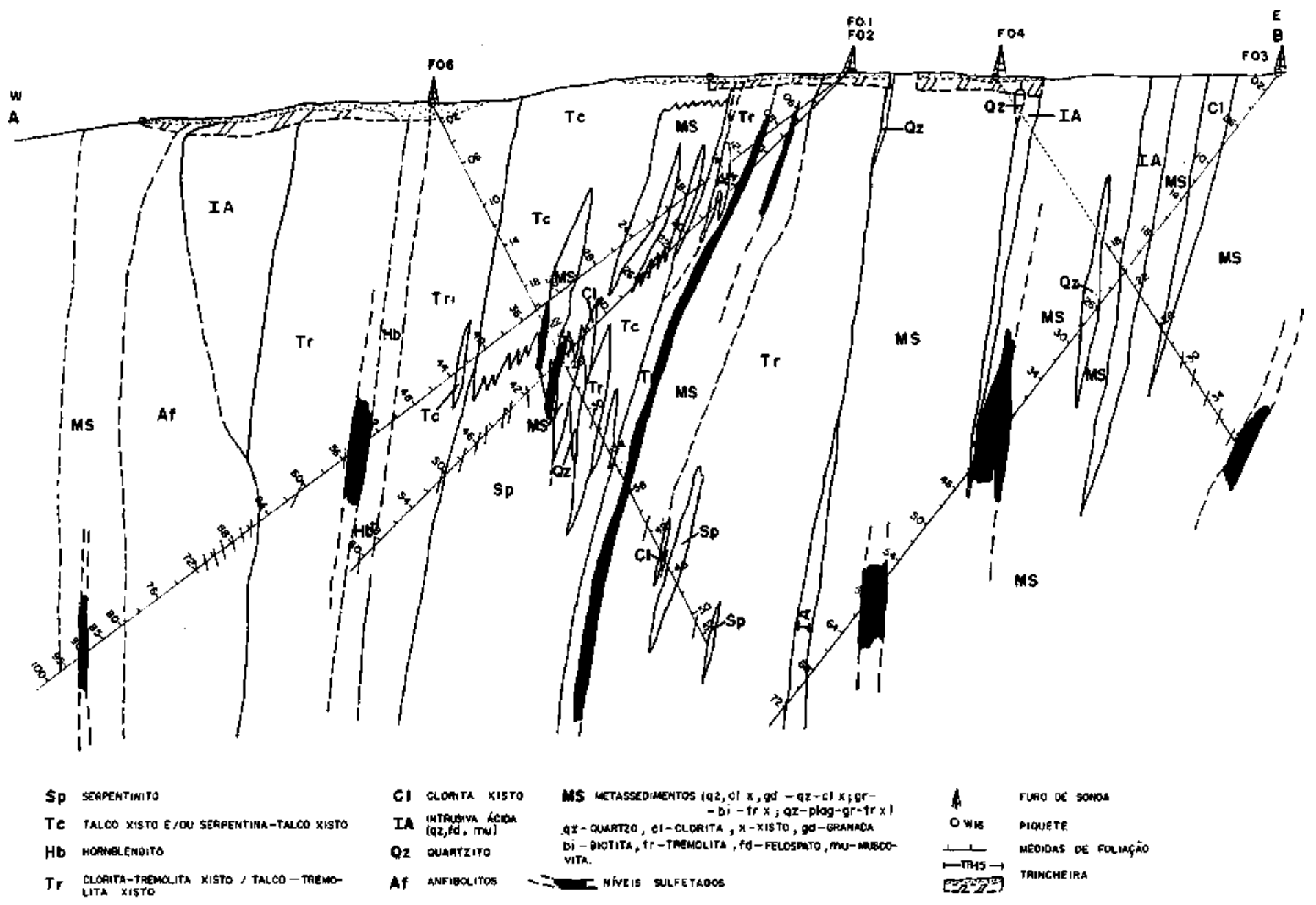

Figura 6 - Perfil litoestrutural da porção norte da Seqüência Vulcano-Sedimentar de Alpinópolis (MG)

Figure 6 - Lithologic and structural section of the northern portion of the Volcanosedimentary Sequence of Alpinópolis, Minas Gerais 

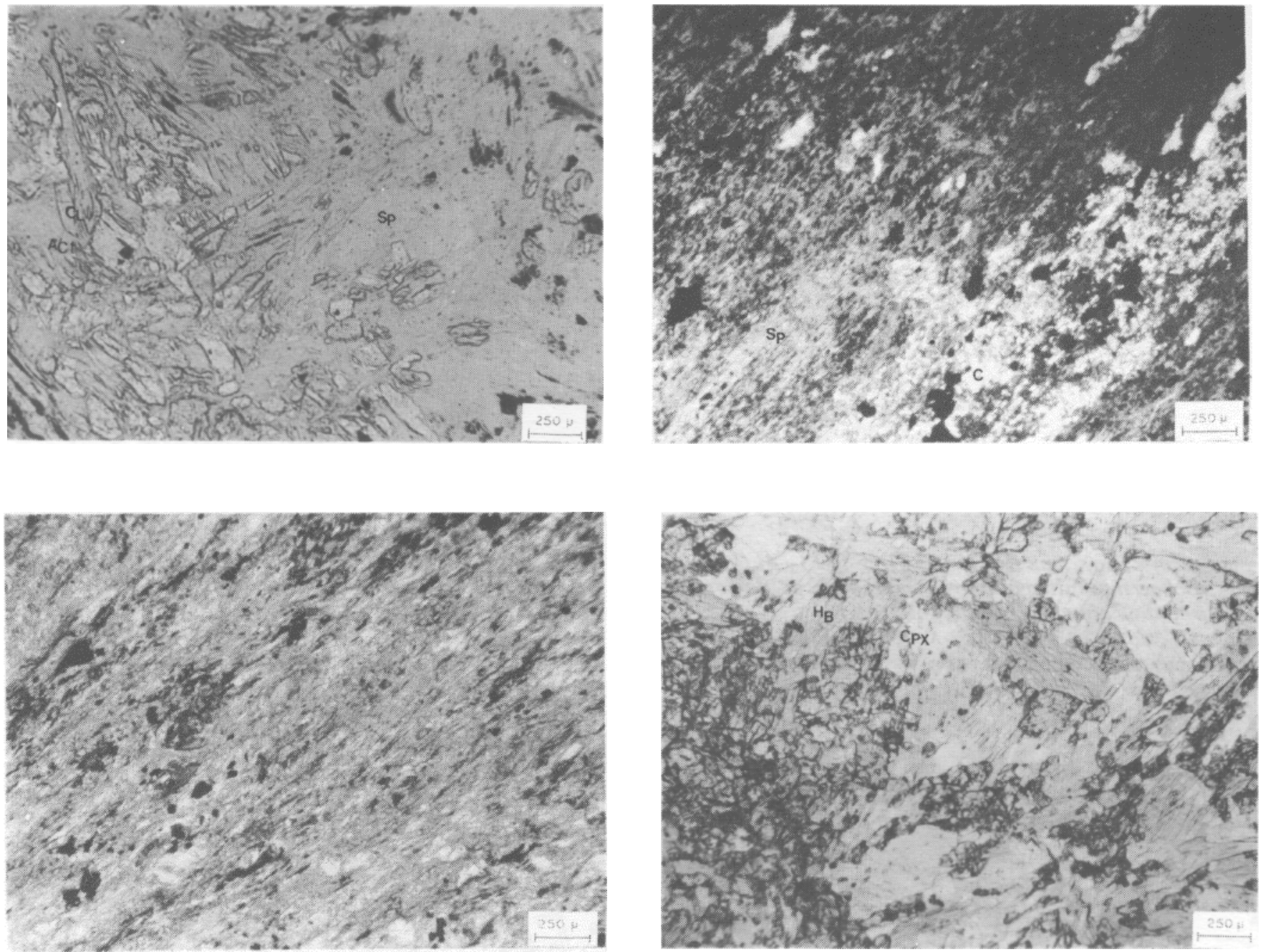

Prancha 2 - Fotomicrografia 3. Cristais de actinolita/tremolita (cores levemente acinzentadas), com clorita associada (coloração cinza), ambos envoltos por massa serpentinítica, com cristais de opacos dispersos. $\boldsymbol{C L}=$ clorita, $\boldsymbol{A C \boldsymbol { T }}=$ actinolital tremolita, SP = serpentina. Nicóis paralelos. Fotomicrografia 4. Carbonatos e opacos associados e preservados na massa serpentinitica. $\boldsymbol{S P}=$ serpentina, $\boldsymbol{C}=$ carbonato, $\boldsymbol{O P}=$ opacos. Nicóis cruzados. Fotomicrografia 5. Xistosidade bem pronunciada em talco xisto, formada pela associação mineral actinolita/tremolita (formas prismáticas) que se transformam para talco e clorita. Nicóis cruzados. Fotomicrografia 6. Metapiroxênio, composto de clinopiroxênio (augita) (coloração cinza mais escuro), com fraturamento cerrado sendo substituídos por anfibólio (actinolita/tremolita) de coloração cinza e clivagem nítida. $\boldsymbol{H} \boldsymbol{B}=$ actinolita/tremolita, $\boldsymbol{C P} \boldsymbol{X}=$ augita. Nicóis paralelos

Chart 2 - Photomicrograph 3. Actinolite-tremolite crystals (light gray) and associated chlorite crystals (medium gray) inside a serpentine matrix. Matrix has some scattered opaque minerals $(\mathbf{C L}=$ chlorite, $\mathbf{A C T}=$ actinolite and tremolite, $\mathbf{S P}=$ serpentine $)$. Plain light. Photomicrograph 4. Carbonates and associated opaque minerals occur in a serpentine matrix ( $\mathbf{S P}=$ serpentine, $\mathbf{C}=$ carbonates, $\mathbf{O P}=$ opaque minerals). Crossed nicols. Photomicrograph 5. Strongly oriented prismatic habit of actinolite - tremolite crystals imparts cleavage to schistose rock. Cleavage becomes enhanced by the transformation of the actinolite - tremolite association into a talc-chlorite association. Crossed nicols. Photomicrograph 6. Metapyroxenite composed of fractured augite (darker gray) that has been partly replaced by tremolite-actinolite with pronounced cleavage (light gray). $(\mathbf{H B}=$ tremolite-actinolite, $\mathbf{C P X}=$ augite). Plain light

sombra de pressão, fraturamento de sillimanita e porfiroclastos de pirita e pirrotita com moagem nas bordas, nas rochas metassedimentares; e a presença de sericita, albita, epídoto e clorita em rochas ácidas. Esses minerais se arranjam segundo as seguintes associações mineralógicas: 1. actinolita/tremolita + clorita + serpentina + talco (metapiroxênitos e metaperidotitos); 2. serpentina + talco (metaperidotitos); 3. serpentina + carbonato (Fotomicrografia 4) (xistos ultramáfícos); 4. clinozoisita + actinolita/tremolita + quartzo (Fotomicrografia 9) (anfíbolitos, xistos, fels e quartzitos); 5. sericita - epídoto - clorita - albita (anfíbolitos, xistos máficos e gnaisses).

Segundo Winkler (1976), as paragêneses acima são indicativas de metamoríismo de grau baixo, fácies xisto-verde, zona da clorita, mas que atingiu os limites superiores da fácies xisto-verde, conforme demonstram as associações 4 e 5. A mineralogia formada durante esse metamorfismo define a foliação mais evidente na área, caracterizada como $\mathrm{C}_{2} /$ $\mathrm{S}_{2}$ (Carvalho 1990) gerada em conseqüência da aloctonia da seqüência (Soares et al 1990).

CONCLUSÕES Os trabalhos de mapeamento geológico, integrando dados de superfície e subsuperfície, acompanhados ainda de estudos petrológicos realizados na Seqüência Vulcano-Sedimentar Alpinópolis, permitiram caracterizar a presença de quatro unidades litologicamente distintas a saber:

- unidade metaultramáfica - constituída por cloritaactinolita/tremolita xistos, onde é possível observar a presença de cristais de olivina e clinopiroxênio e de textura 
Tabela 3A - Mineralogia e transformações metamórficas na unidade metamáfica

Table 3 A - Mineralogy and metamorphic changes of the metamorphosed mafic unit

\begin{tabular}{|c|c|c|c|}
\hline \multicolumn{4}{|c|}{ UNIDADE METABASICA / METAMAFCA } \\
\hline LITOTIPO & $\begin{array}{l}\text { VARIAÇAOO } \\
\text { MINERALOGICA }\end{array}$ & $\begin{array}{l}\text { TRANSFORMACOES } \\
\text { METAMORFICAS } \\
\text { MAIS FREQUENTES } \\
\text { NOS LITOTIPOS }\end{array}$ & $\begin{array}{c}\text { POSSIVEL ROCHA } \\
\text { ORIGNAL }\end{array}$ \\
\hline $\begin{array}{l}\text { Plagioclásio-Hornblenda } \\
\text { Act/Tremolita Xisto }\end{array}$ & $\begin{array}{l}\text { Anfibolio }=30-65 \% \\
\text { Biotita }=0-40 \% \\
\text { Ptagioclasio }=8-15 \% \\
\text { Epidoto, Sericita } \\
\text { Carbongto }=3-18 \% \\
\text { Titanita }=0-8 \% \\
\text { Quartzo }=1-12 \% \\
\text { Clorita }=0-2 \% \\
\text { Espind́lio }=0-1 \%\end{array}$ & 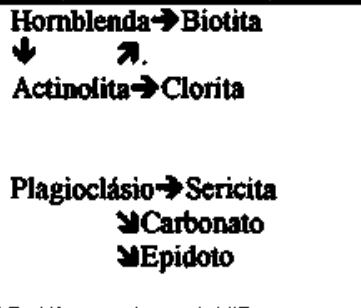 & $\begin{array}{l}\text { Basaltos Tolefticos } \\
\text { (T) }\end{array}$ \\
\hline Anfibolito & $\begin{array}{l}\text { Anfibolio }=48-65 \% \\
\text { Plagioclásio }=25-40 \% \\
\text { Augita }=0-20 \% \\
\text { Epidoto }=3-10 \% \\
\text { Sericita }=2-6 \% \\
\text { Carbonato }=0-4 \% \\
\text { Opacos }=0-3 \% \\
\text { Biotita }=0-1 \%\end{array}$ & $\begin{array}{c}\text { ABiotita } \\
\text { Homblenda- } 4 \text { Act/Tremolita } \\
\text { MAugita } \\
\text { ACarbonato } \\
\text { Plagioclasio } \rightarrow \text { Epidoto } \\
\text { MClorita } \\
\text { MSericita }\end{array}$ & $\begin{array}{l}\text { Basaltos Tolefticos } \\
\text { () }\end{array}$ \\
\hline
\end{tabular}

spinifex pseudomorfizada; serpentinitos com proporções variadas de tremolita/actinolita, clorita, carbonato e olivinas; talco xistos e hornblenda xistos. Caracterizam os komatiítos de composição peridotítica a piroxenítica.

- unidade metamáfica - representada por $1 \mathrm{i}$ totipos, tais como plagioclásio-hornblenda-tremolita/actinolita xistos e anfibolitos, que química e mineralogicamente indicam associação original correspondente a rochas basálticas de provável afinidade toleítica.

- unidade metassedimentar - formada por granada-biotita xisto, sillimanita-biotita xisto, granada-antofilita xisto, quartzitos, formações ferríferas e, possivelmente, alguns corpos de actinolita/tremolita-biotita xistos e de clinozoisitaactinolita/tremolita fels. Esses litotipos são interpretados como originados a partir de sedimentos tufáceos, pelíticoaluminosos, margosos, chert e formações ferríferas.

- unidade intrusiva ácida - representada por rochas de composição essencialmente trondjemítica a monzogranítica, cuja mineralogia essencial é dada por quartzo, plagioclásio e biotita. Apesar da sua deformação, exibe contatos nitidamente discordantes, com as demais unidades, sendo portanto considerada tardia em relação à primeira deformação. Localmente, quando em contato com a unidade metaultramáfica, apresenta mudanças mineralógicas com a formação de marunditos.

Os eventos tectônico-metamórficos com caráter policíclico que atuaram na área resultaram numa geologia excepcionalmente complexa, afetando a distribuição e a configuração espacial dos corpos litológicos, mas permitindo ainda a reconstituição de pelo menos dois destes eventos. O primei- ro alcançou temperaturas de pelo menos $600^{\circ} \mathrm{C}$, marcado pela associação mineralógica granada/sillimanita/estaurolita. $\mathrm{O}$ segundo evento foi retrogressive, na fácies xisto-verde, e provocou extensivas modificações mineralógicas tais como cloritização, serpentinização, carbonatação e silicifícação, associando-se ao evento principal de cisalhamento e aloctonia da seqüência.

A presença de rochas komatíiticas, marcadas por textura spinifex, teores de $\mathrm{MgO}$ superiores a $18 \%$ em base anidra (Arndt e Nisbet 1982), dos sedimentos químicos e o contexto regional sugerem que a Seqüência Vulcano-Sedimentar Alpinópolis tenha se formado originariamente por vulcanismo básico/ultrabásico. Pausas ou interrupcões desse vulcanismo foram acompanhadas pela deposição de sedimentos tufáceos, aluminosos e/ou margosos, cherts e formação ferrífera. No decorrer do tempo geológico, todo o conjunto vulcanosedimentar sofreu metamorfismo, tectonismo e intrusões de rochas granitóides, com possível transporte e enclave tectônico sobre o embasamento siálico. Eventos posteriores alteraram a geometria e o arranjo original dos corpos.

Agradecimentos Agradecimentos especiais são devidos ao engenheiro José Tarcísio Soares e ao sr. João Soares (in memorian), pelo apoio financeiro dado durante o desenvolvimento dos trabalhos de mapeamentos e sondagens, desenvolvidos entre os anos de 1981 e 1986. Os agradecimentos são extensivos aos colegas e instituições que de uma maneira ou de outra incentivaram ou colaboraram com a execução deste trabalho.

\section{REFERÊNCIAS BIBLIOGRÁFICAS}

ARNDT, N.T. \& NISBET, E.G. 1982. What is a Komatiite? In: ARNDT, N.T. \& NISBET, E.G. eds. Komatiites. London, George Allen \& Unwin. p. $19-27$.

CARVALHO, S.G.; CHOUDHURI, A.; OLIVEIRA, M.A.F.; FIORI, A.P.; SOARES, P.C. 1982.- Paragènese e possível origem dos xistos básicos e ultrabásicos de Fortaleza de Minas, MG. In: CONOR. BRAS. GEOL. 32. Salvador, 1982. Anais... SBG, Salvador, v. 2. p. 641-647.

CARVALHO, S.G. \& BATISTA, J.J. 1983. Prospecçâo geoquímica de solo no cinturão vulcano-sedimentar "Morro do Ferro", Fortaleza de Minas (MG). In: SIMP. GEOL. MINAS GERAIS, 2. Belo Horizonte, 1983. Atas... SBG, Belo Horizonte, bol. 3 p. 248-258.

CARVALHO, S.G. 1990. Geologia, petrologia e metalogenia da seqüência vulcano-sedimentar Alpinópolis (MG). São Paulo. 216 p. (Tese de Doutoramento, IG/USP).

CAVALCANTE, J.C.; CUNHA, L.C.: CHIEREGATI, C.A.; YAMAMOTO, K.; DRUMOND, J.B.V.; ROSA, D.B.; ROCHA, J.M.; COUTINHO, 

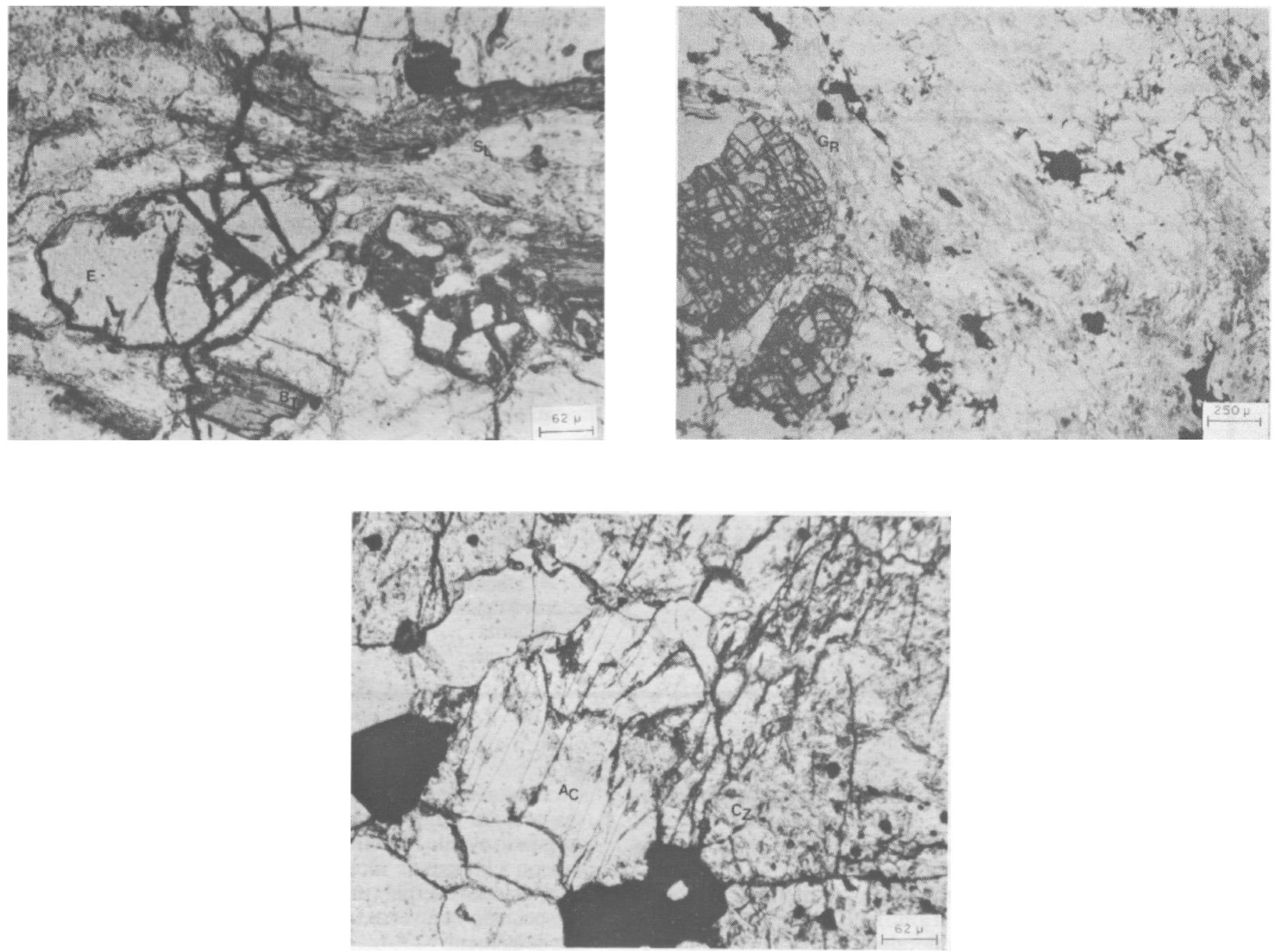

Prancha 3 - Fotomicrografia 7. Associação mineral de estaurolita (relevo mais alto), sillimanita (hábito acicular), biotita e quartzo em metapelito. Localmente observa-se sillimanita, sofrendo processos de serieitização. $\boldsymbol{E}=$ estaurolita, $\boldsymbol{S} \boldsymbol{L}=$ sillimanita, BT - biotita. Nicóis paralelos. Fotomicrografia 8. Granada antofilita xisto, mostrando matriz composta por cristais de plagioclásio, feldspato potássico e predominantemente cristais de antofilita que marcam uma orientaçấo preferencial. $\mathbf{G R}=$ granada. Nicóis paralelos. Fotomicrografia 9. Associações mineral constituida por clinozoísita (coloração cinza mais escuro), actinolita/tremolita (cinza claro), com formas mais ou menos tabulares e opacos em clinozoisita-actinolitafels. $\boldsymbol{C Z}=$ clinozoisita, $\boldsymbol{A C}=$ actinolita/tremolita. Nicóis paralelos

Chart 3 - Photomicrograph 7. The staurolite-sillimanite-biotite-quartz association define a metapelite: staurolite (high relief) and sillimanite (acicular habit). In places sillimanite undergoes sericitization $(\mathbf{E}=$ staurolite, $\mathbf{S L}=$ sillimanite, $\mathbf{B T}=$ biotite). Plain light. Photomicrograph 8. Garnet-antophylite schist. Garnet occurs as large porphyroblasts in a matrix predominantly composed of antophyllite with subordinate plagioclase and potash feldspar. $(\mathbf{G R}=$ garnet). Plain light. Photomicrograph 9. Clinozoisite-actinolite fels with clinozoisite (darker gray), tabular-shaped actinolite-tremolite (light gray) and opaque minerals $(\mathbf{C Z}=$ clinozoisite, AC $=$ actinolite-tremolite). Plain light

M.G.M. 1979. Projeto Sapucai. São Paulo, CPRM-DNPM. (Mapa e Relatório Final).

CHOUDHURI, A · SZABÓ, G.J.A · EBERT, H.D. 1982. Feições estruturais e texturais dos derrames ultramáfícos a norte e nordeste de Petunia, sul de Minas Gerais. Ciências da Terra. 7:18-20.

DEER, W.A.; HOWIE, R.A.; ZUSSMAN, J. 1966. Minerais Constituintes das Rochas- Uma Int rodução. Lisboa, Fundação Calouste Gulbenkian. 558 p. (Trad. Luis E. Nabais Conde, 1981).

HEILBRON, M.; VALERIANO, C.M.; ZIMBRES, E.; CHRISPIM, S.J.; SIMÕES, L.S.A.; SOUZA, M.A.T. 1987. O contato basal do Grupo Canastra entre Itaú de Minas e Carmo do Rio Claro, MG. In: SIMP. GEOL. MINAS GERAIS, 4. Belo Horizonte, 1987. Anais... Belo Horizonte, SBG. bol. 7, p. 179-198

JENSEN, L.S. 1976. A New Cation Plot for Classifying Sub-Alkalic Volcanic Rocks. Ontario, Division of Mines. Misc. Paper 66.

MARCHETTO, C.M.L.; BRENNER, T.L.; FRANKE, N.D.; CHENEY, J.T.; TEIXEIRA, N. A; MOREIRA, A.E.; PIMENTEL, R.C.; GALLO, C.B.M. 1984. Geologia e petrografia do segmento do Greenstone Belt Morro do Ferro a sul de Fortaleza de Minas. In: CONOR. BRAS. GEOL., 33. Rio de Janeiro, 1984. Resumos... Rio de Janeiro, SBG. p. 149.

MORALLES, N.; CARVALHO, S.G.; OLIVEIRA, M.AF; RODRIGUES, M.F.B.; ZANARDO, A. 1983. Geologia das Folhas de Fortaleza de Minas, Alpinópolis, Jacuí e Nova Rezende. In: SIMP. REG. GEOL. MINAS
GERAIS, 2. Belo Horizonte, 1983. Atas... Belo Horizonte, SBG/NMG. p. 411-422.

NALDRETT, A. J. \& TURNER, A.R. 1977. The geology and petrogenesis of a greenstone belt and related nickel sulfide mineralization at Yakabindie, Western Australia. Precambrian Res. . 5:43-103.

SIMÕES, L.S.A; VALERIANO, C.M.; ZANARDO, A.; MORALLES, N.; GOMI, C,; MORAES, R. 1988. Zonação metamórfica inversa do Grupo Araxá/Canastra na região de São Sebastião do Paraíso - Alpinópolis. In: CONOR. BRAS. GEOL., 35. Belém, 1988. Anais... Belém, SBG. v. 3, p. 1203-1216.

SZABÓ, J.A.G. 1989. Contexto Geológico e Petrologia das Rochas Metaultramáficas de Alpinópolis (MG). São Paulo. 203 p. (Dissertação de Mestrado, IG-USP).

TEIXEIRA, N. A. 1978. Geologia e Petrologia e Prospecção Geoquímica da Seqüencia Vulcano-Sedimentar Morro do Ferro, Fortaleza de Minas $(M G)$. Brasília. (Dissertação de Mestrado, IG-UnB).

TEIXEIRA, N. A \& DANNI, J.C.M. 1979a. Geologia da raiz de um greenstone belt na região de Fortaleza de Minas, Minas Gerais. Rev. Bras. Geoc.. 9(1): 17-26.

TEIXEIRA, N.A, \& DANNI, J.C.M. 1979b. Petrologia de lavas metabásicas da Seqüência Vulcano Sedimentar Morro do Ferro, Fortaleza de Minas (MG). Rev. Bras. Geoc.. 9(2): 151-158.

TEIXEIRA, N.A; GASPAR, J.C.; BRENNER, T.L.; CHENEY, J.T.; E 
Tabela 3B - Mineralogia e transformações metamórficas na unidade metassedimentar Table 3 B - Mineralogy and metamorphic changes of the metasedimentary unit

\begin{tabular}{|c|c|c|c|}
\hline \multicolumn{4}{|c|}{ UNIDADE METASSEDIMENTAR } \\
\hline LJTOTIPO & $\begin{array}{c}\text { VARJAC̄O } \\
\text { MINERALOOICA }\end{array}$ & $\begin{array}{l}\text { TRANSFORMACOES } \\
\text { METAMÓRFICAS } \\
\text { MAIS FREQUENTES } \\
\text { NOS LITOTIPOS }\end{array}$ & $\begin{array}{l}\text { POSSIVEL ROCHA } \\
\text { ORIGINAL }\end{array}$ \\
\hline Granada- Biotita Xisto & $\begin{array}{l}\text { Biotita }=2-40 \% \\
\text { Granada }=3-35 \% \\
\text { Plagioclásio }=6-45 \% \\
\text { Quartzo }=2-20 \% \\
\text { Clorita }=2-19 \% \\
\text { Sericita }=0-4 \% \\
\text { Epidoto }=0-2 \%\end{array}$ & $\begin{array}{c}\text { Biotita } \rightarrow \text { Clorita } \\
\text { NClorita } \\
\text { Plagioclásio } \rightarrow \text { Sericita } \\
\text { YEpidoto }\end{array}$ & Tufos + Pelitos ? \\
\hline AcL/Tremolita Biotita Xisto & $\begin{array}{l}\text { Biotita }=2-38 \% \\
\text { Plagioclásio }=8-38 \% \\
\text { Act/Tremolita }=2-32 \% \\
\text { Quartzo = 5-28\% } \\
\text { Clorita }=0-22 \% \\
\text { Opacos }=4-15 \% \\
\text { Sericita, Espinelio, } \\
\text { Epidoto = 0-2\% }\end{array}$ & $\begin{array}{c}\text { 7Epidoto } \\
\text { Plagioclásio-\$Sericita } \\
\text { YCarbonato } \\
\text { YClorita } \\
\text { Actinolita/Tremotita } \rightarrow \text { Biotita } \\
\text { YClorila }\end{array}$ & $\begin{array}{c}\text { Possiveis sedimentos } \\
\text { composiçâo tufácea e } \\
\text { margosa }\end{array}$ \\
\hline $\begin{array}{l}\text { Sillimanita-Biotita Xisto } \\
\text { portadores de Granada } \\
\text { Estaurolita }\end{array}$ & $\begin{array}{l}\text { Quartzo = 39\% } \\
\text { Plagioclásio = 35\% } \\
\text { Biotita }=10 \% \\
\text { Sillimanita }=8 \% \\
\text { Estaurolita }=4 \% \\
\text { Sericita }=3 \% \\
\text { Granada }=1 \% \\
\text { Apatita e Opacos = } 1 \%\end{array}$ & $\begin{array}{l}\text { Sitlimanita } \rightarrow \text { Sericita } \\
\text { Plagioclásio } \rightarrow \text { Sericila }\end{array}$ & Pelitos \\
\hline Granada Antofilita Xisto & $\begin{array}{l}\text { Antofilita }=30-40 \% \\
\text { Clorita }=0-30 \% \\
\text { Granada }=0-20 \% \\
\text { Microclínio }=0-17 \% \\
\text { Quartzo }=0-10 \% \\
\text { Plagioclásio }=0-10 \% \\
\text { Biotita }=0-6 \% \\
\text { Opacos }=0-5 \% \\
\text { Espinélio }=0-4 \%\end{array}$ & $\begin{array}{l}\text { AClorita } \\
\text { Antofilita } \\
\text { YBiotita }\end{array}$ & Turos? \\
\hline $\begin{array}{l}\text { Clinozoisita Actinolita } \\
\text { Quartzo Fels }\end{array}$ & $\begin{array}{l}\text { Quartzo }=40 \% \\
\text { Act } / \text { Tremolita }=30 \% \\
\text { Clinozoisita }=25 \% \\
\text { Titanita }=2 \% \\
\text { Opacos }=3 \%\end{array}$ & Clinozoisita $\rightarrow$ AcL/Tremolita & Margas ? \\
\hline $\begin{array}{l}\text { Quartzitos e } \\
\text { Formaçăo Fcrrifera }\end{array}$ & $\begin{array}{l}\text { Quartzo }=50-100 \% \\
\text { Hematita }=0-50 \% \\
\text { Sericita }=0-3 \%\end{array}$ & & $\begin{array}{l}\text { Chers } \\
\text { ferruginosos }\end{array}$ \\
\hline
\end{tabular}

MARCHETTO, C.M.L. 1987. Geologia e implicações geotectônicas do greenstone belt Morro do Ferro (Fortaleza de Minas - MG). Rev. Bras. Geoc., 17:209-220.

VILJOEN, M.J.; VILJOEN, R.P.; PEARTON, T.N. 1982. The nature and distribution of Archaean komatiite volcanics in South Africa. In: ARNDT, N.T. \& Nisbet, E.G. eds. Komatiites. London, George Allen \& Unwin. p. 53-79.
WINKLER, H.G.F. 1976. Petrogênese das Rochas Metamórficas. São Paulo, Edgard Blucher. (Trad. Carlos Burger Jr.). 254 p.

MANUSCRITO A722

Recibo em 22 de maio de 1992

Revisão do autor em 28 de novembro de 1994 Revisão aceita em 17 de dezembro de 1994 